\title{
Cyclical Thrombocytopenia: Characterization by Spectral Analysis and a Review
}

\author{
JOANNA L. SWINBURNE ${ }^{\mathrm{a}}$ and MICHAEL C. MACKEY ${ }^{\mathrm{b}, *}$ \\ ${ }^{\mathrm{a} D e p a r t m e n t ~ o f ~ P h y s i o l o g y, ~ C e n t r e ~ f o r ~ N o n l i n e a r ~ D y n a m i c s, ~ M c G i l l ~ U n i v e r s i t y ; ~}{ }^{\mathrm{b}}$ Departments of Physiology, Physics, and \\ Mathematics, Centre for Nonlinear Dynamics, McGill University
}

(Received I October 1998; In final form 12 March 1999)

\begin{abstract}
We have analyzed published platelet time series in four normal individuals and 29 putative cyclical thrombocytopenia patients for evidence of significant $(p \leq 0.05)$ cyclicity. Three of the normal individuals (all males) showed significant cycling (periods $T$ of 23, 30 and 31 days) as did 15 of the cyclical thrombocytopenia patients ( $T$ from 13 to 65 days). Cyclical thrombocytopenia seems to be approximately equally prevalent in women and men, though in cases where a definite etiology was suggested an autoimmune origin occurs more frequently in women. We also briefly review the current state of knowledge of the control of platelet production by thrombopoietin (c-Mpl ligand) and previous attempts that have been made to construct mathematical models for the platelet control system.
\end{abstract}

\section{INTRODUCTION}

Periodic hematological diseases are unusual and fascinating in that the numbers of one or more of the circulating blood cells (red cells, white cells, platelets) spontaneously oscillate with periods on the order of days to months Haurie et al. (1998). They are classical examples of dynamical diseases [Glass and Mackey (1988)]. In some of these diseases, such as cyclical neutropenia [Haurie et al. (1999a,b, 1998); Haurie and Mackey (1999); Hearn et al.
(1998)] and periodic chronic myelogenous leukemia [Fortin and Mackey (1999)], there is clear evidence for statistically significant cycling of all of the major blood cell groups with the same period in a given subject. It is generally thought that these disorders involve a destabilization at the pluripotential stem cell (PPSC) level such that there is an oscillatory efflux of cells into all differentiation pathways [Mackey (1978, 1979a, 1996)]. In other dynamic hematological diseases like periodic auto-immune hemolytic anemia [Bélair et al. (1995); Kirk et al.

\footnotetext{
*Corresponding Author: Tel: (514) 398-4336; Fax: (514) 398-7452; E-mail: mackey@cnd.mcgill.ca; 3655 Drummond Street, Room 1124, Montreal, Quebec, CANADA H3G 1 Y6
} 
(1968); Mackey (1979b); Mahaffy et al. (1998); Orr et al. (1968)] there is an oscillation in only one of the major blood cell types. Cyclical thrombocytopenia $(\mathrm{CT})$ is a rare blood disease apparently falling into this second category.

Cyclical thrombocytopenia is characterized by a periodic rise and fall in circulating platelet counts, generally from normal to below normal values. This disease is associated with a number of bleeding symptoms which have no apparent origin other than the thrombocytopenia. Cyclical thrombocytopenia, like periodic auto-immune hemolytic anemia, probably involves a destabilization of a single peripheral control loop mediated by one or more circulating cytokine regulators.

Cyclic thrombocytopenia has been previously reported with periods between 20 and 40 days [Aranda and Dorantes (1977); Balduini et al. (1993); Bernard and Caen (1962); Brey et al. (1969); Caen et al. (1964); Chintagumpala et al. (1992); Cohen and Cooney (1974); Dan et al. (1991); Demmer (1920); Engstrom et al. (1966); Goldschmidt and Fono (1972); Lewis (1974); Skoog et al. (1957); Tefferi et al. (1989); Wasastjerna (1967); Wilkinson and Firkin (1966); Yanabu et al. (1993)] and reviewed by Cohen and Cooney (1974). It has also been reported that oscillations could be detected in the platelet counts of normal individuals with the same range of periods [Morley (1969); von Schulthess and Gessner (1986)].

We have identified 29 clinical reports of putative cyclical thrombocytopenia and four reports of platelet cycling in normal individuals. Using techniques developed in astrophysics for the detection of statistically significant periodicity in unevenly sampled data, we have examined these clinical studies to determine the nature of platelet cycling in normals and in cyclical thrombocytopenia. Following a review of platelet production and control and cyclical thrombocytopenia in Section 2, and a brief description of our data selection criteria and analysis methods in Section 3, we present our main results in Section 4. The paper concludes with a brief discussion in Section 5.

\section{THROMBOPOIESIS AND CYCLICAL THROMBOCYTOPENIA}

\subsection{Platelet Production and Control}

Platelets are important for the body's clotting response to injury as well as day to day blood vessel repair. The mechanism of platelet formation is complex and not fully understood. Platelets arise from large megakaryocytes found in the bone marrow, which are derived from pluripotential hematopoietic stem cells. Mature megakaryocytes do not proliferate, but the megakaryocyte compartment is maintained by an approximately constant influx of progenitor cells [Branehog et al. (1975)]. At a given point in the lifetime of the immediate precursor to the megakaryocyte, the megakaryoblast, mitosis ceases. With the cessation of mitosis, megakaryocytes begin to undergo nuclear endoreduplication. Endoreduplication, or endomitosis, is a process in which DNA replication occurs, and sister chromatids separate, but the cytoplasm remains intact and the cell does not divide [Kuter et al. (1997)]. The megakaryoblast nucleus grows and becomes lobulated. DNA replication usually occurs at least three times during the complete sequence of endoreduplication to yield a mature megakaryocyte of ploidy 16 [Kuter et al. (1997)] capable of platelet production. Megakaryocyte ploidy, however, is variable and can be as high as 128 Ellis et al. (1995).

The immature megakaryocyte has a large nucleus that occupies most of the cell volume. As the nucleus increases its ploidy, the cytoplasmic portion of the polyploid megakaryocyte expands. With the cytoplasmic expansion comes the development of the smooth, internal demarcation membrane system that will eventually become the external membrane of each platelet. Once the demarcation membrane is in place, membrane-bound sections of cytoplasm are pinched off from the megakaryocyte in sausage-like links termed pro-platelets [Beutler et al. (1995)]. One mature megakaryocyte can give rise to between 1000 and 5000 platelets [Beutler et al. (1995)]. 
The primary cytokine responsible for platelet formation, thrombopoietin (TPO), was discovered in 1994 to be the ligand for the c-Mpl receptor, the cellular homologue of the viral oncogene for myeloproliferative leukemia [Eaton and de Sauvage (1997); Kaushansky (1995); Papayannopoulou (1996)]. Thrombopoietin stimulates hematopoietic stem cells to enter the cell cycle from their dormant $G_{0}$ phase [Ritchie et al. (1996)]. TPO also stimulates proliferation and differentiation of megakaryocyte precursors [Tanimukai et al. (1997)], decreases precursor apoptosis [Borge et al. (1996, 1997); Ratajczak et al. (1997); Ritchie et al. (1996, 1997); Zauli et al. (1997)], promotes megakaryocyte maturation [Eaton and de Sauvage (1997); Kaushansky et al. (1995)], increases megakaryocyte ploidy [Kuter et al. (1997)] and stimulates the release of platelets via the fragmentation of mature megakaryocytes [Kuter (1996)]. The effects of TPO can be enhanced when combined with other cytokines [Zeigler et al. (1994)]. These effects of TPO qualitatively mimic the effects of erythropoietin and granulocyte colony stimulating factor in the erythroid and granulocytic lines respectively. Whereas originally it was thought that the effects of thrombopoietin were limited to cells of the megakaryocyte lineage, it is now known that in addition TPO plays a role in myelopoiesis and erythropoiesis and acts on both lineage committed cells and on immature, pluripotential stem cells [Sitnicka et al. (1996); Solar et al. (1998)].

Other cytokines associated with platelet production can be classified into two categories: early acting factors whose effects are widespread, and late acting factors that are specific to the megakaryocyte lineage [Kaushansky (1995)]. The early acting factors, which include interlukin-3 (II-3), the c-kit ligand [KL, also termed stem cell factor (SCF) or steel factor (SF)], and GM-CSF (granulocyte-macrophage colony stimulating factor), are megakaryocyte colony stimulating factors (Meg-CSF's). They are megakaryocyte proliferation factors and their effect is to expand the pool of megakaryocyte-specific hematopoietic progenitors [Kaushansky et al. (1995)]. Late acting factors do not promote megakaryocyte colony formation.
They do, however stimulate megakaryocyte differentiation and maturation. Late acting factors include Interlukin 6 and 11 (II-6 and II-11) and leukemia inhibitory factor (LIF) [Broudy and Kaushansky (1995)]. TPO is thus both an early and a late acting factor in megakaryocyte differentiation [Kaushansky et al. (1995)].

Human platelet levels remain relatively stable for years unless perturbed by disease or pregnancy [Kuter et al. (1997)]. Between species or between individuals within a species, however, platelet counts vary. The normal range for human platelet level is $150-450 \times 10^{9}$ platelets/L blood with an average of $290 \times 10^{9}$ platelets/L. The body tightly regulates platelet mass and not platelet number. TPO plays an important role in this regulatory process [Kuter (1996)].

\subsection{Cyclical Thrombocytopenia}

In cyclical thrombocytopenia, platelet counts oscillate from very low $\left(1 \times 10^{9}\right.$ platelets $/ \mathrm{L}$ blood $)$ to normal $\left(150-450 \times 10^{9} / \mathrm{L}\right)$ or very high levels $\left(2000 \times 10^{9} / \mathrm{L}\right)$. In addition, patients may exhibit one or several of the following symptoms: purpura, petechiae, epistaxis, gingival bleeding, menorrhagia, easy bruising, possibly premensturally, and gastrointestinal bleeding. The period of the platelet oscillation varies between individuals, and has been reported in many cases to be approximately monthly [Kimura et al. (1996); Helleberg et al. (1995); Yanabu et al. (1993); Bernard and Caen (1962)]. In some female patients platelet cycles are reported to be in phase with the menstrual cycle [Tomer et al. (1989); Helleberg et al. (1995)], while other investigators report no correlation with the menstrual cycle [Yanabu et al. (1993); Hoffman (1989); Menitove et al. (1989)]. One group reported that the platelet oscillations were in phase with the patient's menstrual cycle when this was controlled by exogenous hormone therapy, but not in phase with the patient's natural menstrual cycle [Cohen and Cooney (1974)]. 
There are two proposed origins of cyclical thrombocytopenia. One is an auto-immune origin most prevalent in females. The other is of amegakaryocytic origin, most common in males.

Autoimmmune cyclical thrombocytopenia is postulated to be an unusual form of immune thrombocytopenic purpura (ITP) [Beutler et al. (1995)]. In this type of cyclical thrombocytopenia, antiplatelet autoantibodies periodically remove large numbers of platelets from the circulation. The antibodies attack platelet membrane-bound glycoproteins GPIIb/IIIa and, to a lesser extent GPIb/IX, which are specific to platelets. GPIIb/IIIa is the receptor for fibinogen and is essential for clot formation and is thus abundant on platelet membranes. Several investigators [Kimura et al. (1996); Helleberg et al. (1995); Yanabu et al. (1993); Menitove et al. (1989)] have reported cycles of platelet-associated immunoglobin $\mathrm{G}(\mathrm{PAIgG})$ reciprocal to the fluctuations of platelets. There is no explanation for the production of the autoantibodies. Tomer et al. (1989) reported an increase in the expression of macrophage Fcy receptors near the onset of thrombocytopenia. They suggest that the Fcy receptor is in part responsible for the clearance of antibody-coated platelets. Autoimmune cyclical thrombocytopenia is characterized by a shortened platelet life span at the time of decreasing platelet counts [Beutler et al. (1995)] which is consistent with an increase in platelet destruction, high levels of antiplatelet autoantibodies and normal to high levels of bone marrow megakaryocytes. In this type of cyclical thrombocytopenia the platelet oscillations are thought to be due to a cyclical destruction of platelets.

The second type of cyclical thrombocytopenia has a different etiology. In the amegakaryocytic variety platelet oscillations are thought to be due to a cyclical failure in platelet production [Bernard and Caen (1962); Cohen and Cooney (1974); Dan et al. (1991); Engstrom et al. (1966); Hoffman et al. (1989); Lewis (1974)]. This variety is characterized by oscillations in bone marrow megakaryocytes preceding the platelet oscillations [Balduini et al. (1993); Bernard and Caen (1962); Dan et al. (1991); Engstrom et al. (1966)\}. Platelet life span is generally normal [Lewis (1974)] and antibodies against platelets are not detected [Hoffman et al. (1989)]. It is possible that the failure of platelet production could arise at the stem cell level since in at least one case [Kimura et al. (1996)] there were parallel cycles of erythrocytes exactly out of phase with the megakaryocyte cycles. It is thought, however, that in the majority of patients the cycling is at the megakaryocyte level [Dan et al. (1991); Hoffman et al. (1989)].

Kimura et al. (1996) suggest that a cyclical fluctuation in the level of various cytokines is responsible for the oscillations in platelet counts. This group postulates that the fluctuation in cytokines leads to both cyclical platelet production and cyclical platelet destruction and thus both types of CT are involved simultaneously. It is known that plasma concentrations of $\mathrm{c}-\mathrm{Mpl}$ ligand are inversely proportional to circulating platelet numbers [Kuter and Rosenberg (1995); Kuter (1996)] just as the circulating levels of granulocyte colony stimulating factor (G-CSF) are inversely proportional to circulating levels of granulocytes [Layton et al. (1989)]. It has been suggested for both G-CSF [Layton et al. (1989)] and c-Mpl [Kuter (1996)] ligand that their levels are regulated by the mass of their primary cellular population targets (granulocytes and platelets respectively).

\section{DATA AND METHODS}

We identified 33 sets of serial platelet counts published by 23 groups of investigators between 1962 and 1996 in which oscillations in platelet counts of normal individuals or cyclical thrombocytopenia were claimed to exist. Of these, four sets were reported in Goldschmidt and Fono (1972), three each in Morley (1969) and Cohen and Cooney (1974), two by each of Rocha et al. (1991), Dan et al. (1991), von Schulthess and Gessner (1986), and Wilkinson and Firkin (1966), and one in each of Kimura et al. (1996), Helleberg et al. (1995), Kosugi et al. (1994), Yanabu et al. (1993), Balduini et al. (1993), Bussel et al. (1990), Hoffman (1989), 
Menitove et al. (1989), Tefferi et al. (1989), Tomer et al. (1989), Aranda and Dorantes (1977), Lewis (1974), Brey et al. (1969), Caen et al. (1964), and Bernard and Caen (1962). Each data set was scanned using Photoshop 4.0 and digitized using GhostView 2.2 to convert the published platelet counts into a uniform, digitized format for analysis of the period of the oscillations.

The Lomb periodogram, an extension of the Fourier power spectral technique for unevenly sampled data, was used to detect periodicity in each data set. Specifically, let $y_{j}$ be the concentration of platelets as measured at times $t_{j}$, where $j=$ $1, \ldots, N$ and $N$ is the number of data points. The mean and variance of the data values are given by

$$
\bar{y} \equiv \frac{1}{N} \sum_{i=1}^{N} y_{j} \quad \sigma^{2} \equiv \frac{1}{N-1} \sum_{i=1}^{N}\left(y_{i}-\bar{y}\right)^{2} .
$$

Then the Lomb normalized periodogram $P(T)$ at a period $T$ is defined by

$$
\begin{aligned}
P(T) \equiv \frac{1}{\sigma^{2}}\left\{\frac{\left[\sum_{j=1}^{N}\left(y_{j}-\bar{y}\right) \cos \frac{2 \pi\left(t_{j}-\rho\right)}{T}\right]^{2}}{\sum_{j=1}^{N} \cos ^{2} \frac{2 \pi\left(t_{j}-\rho\right)}{T}}\right. \\
+\frac{\left[\sum_{j=1}^{N}\left(y_{j}-\bar{y}\right) \sin \frac{2 \pi\left(t_{j}-\rho\right)}{T}\right]^{2}}{\left.\sum_{j=1}^{N} \sin ^{2} \frac{2 \pi\left(t_{j}-\rho\right)}{T}\right\}}
\end{aligned}
$$

where the constant $\rho$ is defined implicitly by

$$
\tan \left(\frac{4 \pi \rho}{T}\right)=\frac{\sum_{j=1}^{N} \sin \left(4 \pi t_{j} / T\right)}{\sum_{j=1}^{N} \cos \left(4 \pi t_{j} / T\right)} .
$$

$P(T)$ indicates the likelihood of a periodicity with period $T$ in the data.

For any given time series, if the null hypothesis is that the values $y_{j}$ are independent Gaussian random noise, and that $P(T)$ has an exponential probability distribution with unit mean, the significance level ( $p$ value) of any peak in that time series is given by

$$
p \equiv 1-\left(1-e^{-P(T)}\right)^{M}
$$

where $M \approx N$ [Press et al. (1992)].

We implemented Equation 2 for a set of different periods $T$. The estimation of the significance level of $P(T)$ in any given set of platelet counts is straightforward as long as some criteria are satisfied for the choice of the range and the number of periods that are scanned [Fortin and Mackey (1999); Press et al. (1992); Scargle (1982)]. An individual data set was considered periodic if the significance level $p$ of the principal peak in the periodogram satisfies $p \leq 0.05$ (5\%), though the question of significance when multiple time series are analyzed needs further consideration (see the Discussion). An adaptation of the procedure proposed in Press et al. (1992), using Matlab, was used to analyze the digitized data (cf. [Fortin and Mackey (1999); Haurie et al. (1999a, b)] for more details).

\section{RESULTS}

We initially considered all 33 data sets that we found in the published literature. Based on our criterion for statistical significance $(p \leq 0.05)$, 15 of these sets were discarded. Thus, of the 33 data sets, 18 were selected for final analysis. Of the 18 , nine were from female subjects and nine were from males. Table I gives a summary of each study, the period of the oscillations, and the corresponding significance level of the individual time series. Our results are also displayed graphically in Figures 1 and 2 for females and males respectively.

The period of the platelet oscillations, as determined by the periodogram analysis, was $28 \pm 15$ days in the women subjects, and varied from a minimum of 13 days in the female subject of Menitove et al. (1989) to a maximum of 65 days in the female subject from Hoffman (1989). For the males the period was $34 \pm 6$ days with a range of 26 [Goldschmidt and Fono (1972)] to 43 days [Engstrom 
TABLE I A summary of the periodicties (in days) estimated through periodogram analysis with each of their significance levels, when the significance levels $p \leq 0.05$, for the normal individuals and cyclical thrombocytopenia patients identified in this study. AI indicates autoimmune, AM amegakaryocytic, CCHF denotes cyanotic congenital heart failure and C-TPO stands for cycling TPO levels.

\begin{tabular}{lcccc}
\hline Source and Patient ID & Sex & Diagnosis & Period $(T$, days) & Significance $(p)$ \\
\hline Helleberg et al. (1995) & F & AI & 27 & 0.0299 \\
Yanabu et al. (1993) & F & Al & 24 & 0.0273 \\
Rocha et al. (1991), Figure 1 & F & AI & 21 & 0.0019 \\
Menitove et al. (1989) & F & AI & 13 & 0.0050 \\
Kosugi et al. (1994) & F & AI & 27 & 0.0061 \\
Hoffman et al. (1989) & F & AM & 65 & $1.62 \times 10^{-4}$ \\
Goldschmidt and Fono (1972), Pat. 4 & F & CCHF & 22 & 0.0277 \\
Cohen and Cooney (1974), Figure 2 & F & AM & 27 & $8.63 \times 10^{-5}$ \\
Lewis (1974) & F & C-TPO & 24 & 0.0061 \\
Kimura et al. (1996) & M & AM \& AI & 36 & 0.0405 \\
Aranda (1977) & M & AM & 28 & 0.0410 \\
Wilkinson and Firtin (1966) & M & AM & 38 & $5.70 \times 10^{-5}$ \\
Engstrom et al. (1966) & M & AM & 43 & $2.47 \times 10^{-9}$ \\
Bernard and Caen (1962) & M & AM & 32 & $4.08 \times 10^{-4}$ \\
Goldschmidt and Fano (1972), Pat. 8 & M & CCHF & 26 & 0.0393 \\
Morley (1969), Subj. 8 & M & Healthy & 30 & 0.0123 \\
von Schulthess and Gessner, Case 1 & M & Healthy & 23 & 0.0017 \\
von Schulthess and Gessner. Case 2 & M & Healthy & 31 & 0.0019 \\
\hline
\end{tabular}

et al. (1966)]. We noted that, on average, the periods of the oscillations in the auto-immune type data (range from 13 to 36 days) were shorter than the period of the amegakaryocytic CT data which ranged from 27 to 65 days. Although there were insufficient numbers of data sets to draw firm statistically significant conclusions, this observation will be an interesting line to investigate.

There was no apparent correlation between the period of the platelet oscillation, the mean platelet count, or the amplitude of the platelet oscillation.

In five of the nine female subjects, the investigators claimed an auto-immune origin for the disease. One female case appeared to be amegakaryocytic. One child had cyclical thrombocytopenia associated with cyanotic congenital heart disease. In five of the male subjects an amegakaryocytic origin was implicated, one had cyanotic congenital heart disease, and three were healthy.

Morley (1969) von Schulthess and Gessner (1986) reported oscillations in the platelet counts of healthy subjects who did not exhibit bleeding symptoms. The data from three of these individuals showed significant cycling.

\section{DISCUSSION AND CONCLUSIONS}

Prehaps the most vexing statistical issue of this study is the assignment of the likelyhood of significance. Given only one of any of the 18 time series for which $p \leq 0.05$, then the significance (relative to the possibility that the time series was generated by noise) is clear: it is the $p$ value quoted in Table 1. However, given the fact that we had multiple data sets in which we found significance $(p \leq 0.05)$ the question is "What significance level must be choosen to be sure that none of the detected cycling is, in fact, just noise?"

A simple example will suffice, and we consider the hematologically normal individuals first. Since we had data from four normals in which cycling was claimed, in order to make sure with a probability $p \leq 0.05$ that none of the individuals platelet time series would be falsely classified as periodic we would have to take $p \leq 0.05 / 4=0.0125$ (the Bonferroni criteria, Snedecor and Cochran (1980)). With this more rigorous criterion, all three of the normal individuals reported in Table I pass the test of statistically significant cycling at the 0.05 level. 

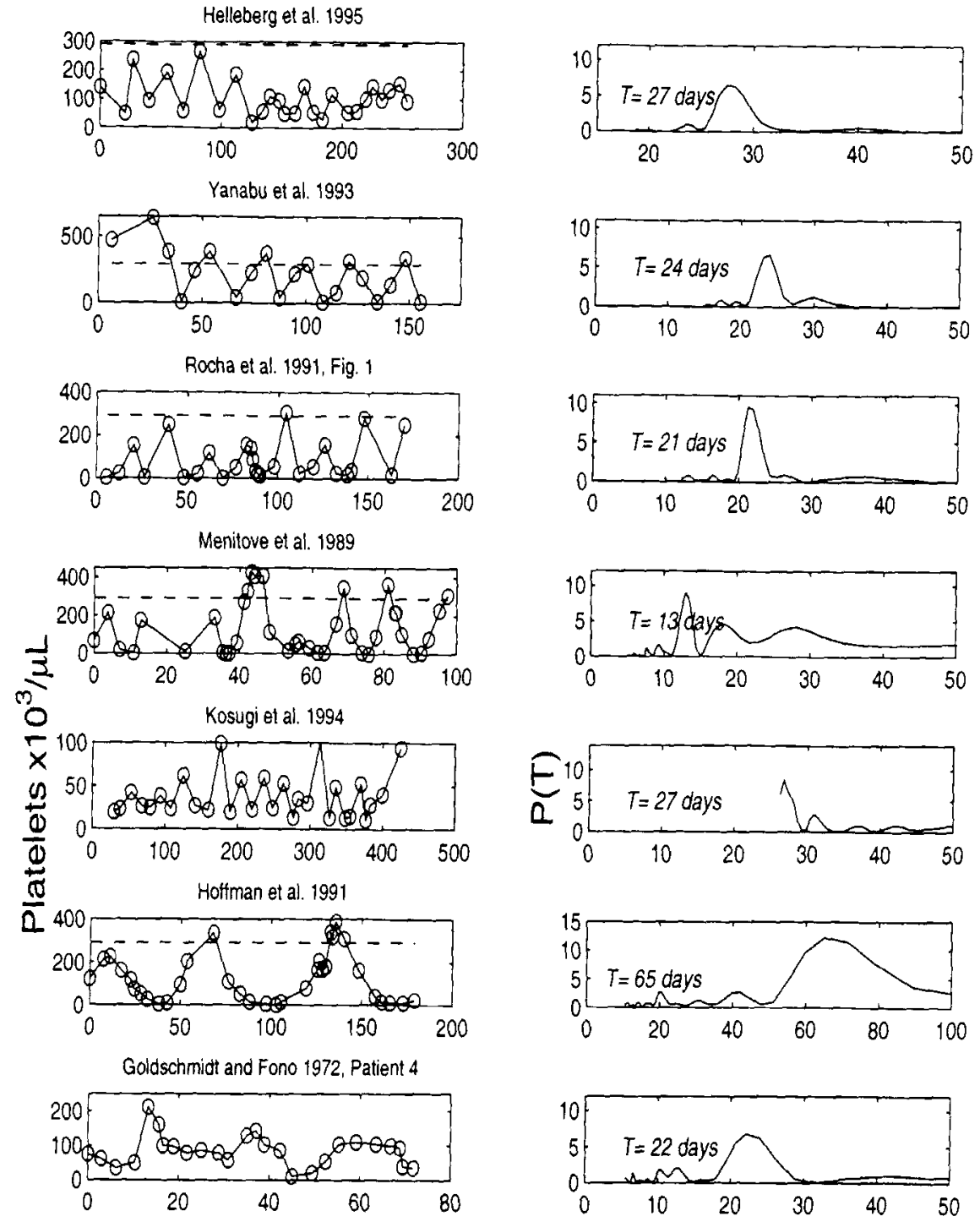

Cohen and Cooney 1974, Fig. 2
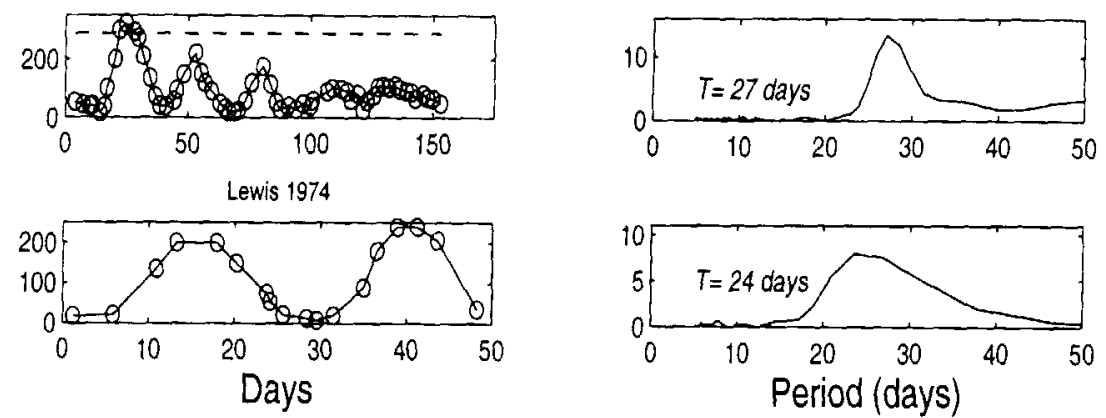

FIGURE I Data and analysis of serial platelet counts for female patients in which there was significant periodicity $(p \leq 0.05)$. The left column contains the serial platelet counts (each identified as to source), and the right column contains the corresponding Lomb periodogram $P(T)$ [power $P$ versus period $T$ in days]. The dashed line in the left column represents the average normal platelet level. Significance levels of the peak power are given in Table I. 

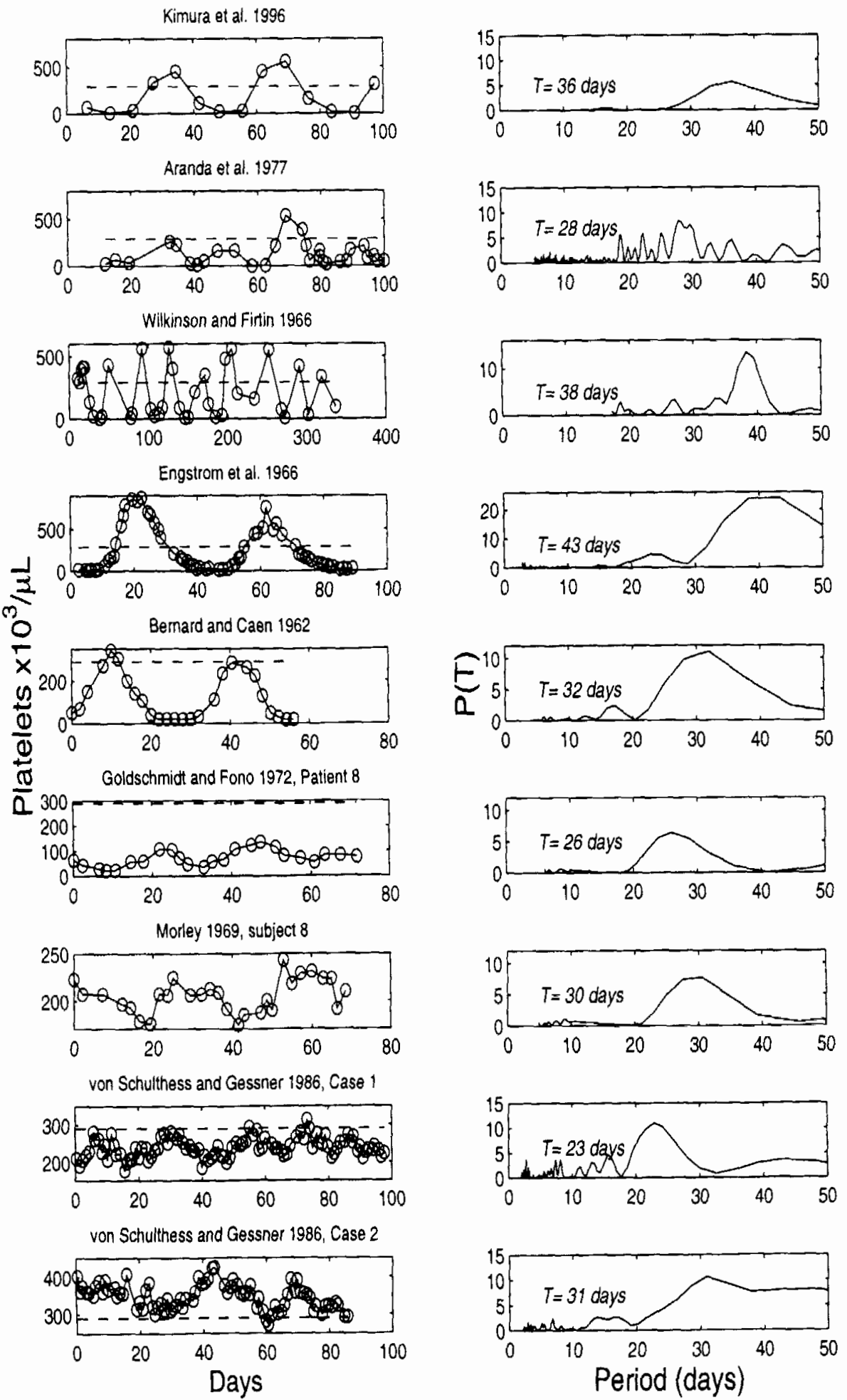

FIGURE 2 As in Figure 1 but for males. 
(Note that with this reasoning, the more data sets that are available in which cycling is susected the more rigorous the criteria that all must pass!).

The situation, however, for the patients with putative cyclical thrombocy-topenia is not so clear cut. In our original data sets we identified 29 claimed cases of cyclical thrombocytopenia. Thus, in order to establish a significance level $p \leq 0.05$ for asserting that we have not mistakenly classified a patient as cycling, we would need to use a significance level criterion of $p \leq 0.05 / 29=0.0017$. At this level, only five of the 15 cyclical thrombocytopenia patients listed in Table I pass. Nevertheless, whatever criterion is selected it is clear that there are incidences of cyclical thrombocytopenia in these data sets.

A few authors have formulated models for the regulation of thrombopoiesis [Bélair and Mackey (1987); Eller et al. (1987); Gray and Kirk (1971); Györi and Eller (1987); von Schulthess and Gessner (1986); Wichmann et al. (1979)]. Some of these modeis have considered only a simple thrombopoietin feedback [Bélair and Mackey (1987); Gray and Kirk (1971); von Schulthess and Gessner (1986)] while others have been much more physiologically detailed [Eller et al. (1987); Györi and Eller (1987); Wichmann et al. (1979)]. von Schulthess and Gessner (1986) formulated their model to understand the platelet cycling in seven normal individuals (four women and three men) that their time series analysis revealed. Their analysis suggested that the normal platelet control system was biased close to a stability boundary and that this was the origin of the observed oscillatory platelet counts in some normal individuals. Bélair and Mackey (1987) specifically considered cyclical thrombocytopenia. They speculated that elevations in the random destruction rate of platelets could give rise to the characteristic patterns observed in cyclical thrombocytopenia. Though modeling results based on this assumption yielded results qualitatively consistent with the clinical data, there is still much room for further elaboration of this problem.

The origin of the dynamics of cyclical thrombocytopenia is not clear. However, there is every reason to believe that this will soon resolve itself in the face of the determined investigations being carried out at a variety of levels. The range of actions of TPO (briefly detailed in Section 2.1) is hauntingly reminiscent of those of both G-CSF and EPO [Haurie et al. (1998)]. The broad outlines of the normal control of platelet production and its pathological derangement will probably be similar to those discovered for granulocyte regulation [Hearn et al. (1998)] and erythrocyte regulation [Bélair et al. (1995); Mahaffy et al. (1998)]. Though the details of a viable model for the control of platelet production via TPO are unclear, it is clear that platelet production shares many qualitative similarities with the control of erythrocyte production. It would not be unexpected if a model for platelet regulation shared many features in common with models for erythrocyte regulation [Mahaffy et al. (1998)].

\section{Acknowledgments}

This work was supported by the Natural Sciences and Engineering Research Council (NSERC, Canada), and Le Fonds pour la Formation de Chercheurs et I'Aide à la Recherche (FCAR, Québec). We thank an anonymous referee and Dr. Dan Kaplan for advice on statistical significance.

\section{References}

Aranda, E. and Dorantes, S. (1977). Garcia's disease: Cyclic thrombocytopenic purpura in a child and abnormal platelet counts in his family. Scand. J. Haematol, 18, 39-46.

Balduini, C., Stella, C., Rosti, V., Bertolino, G., Noris, P. and Ascari, E. (1993). Acquired cyclic thrombocytopenia thrombocytosis with periodic defect of platelet function. Brit. J. Haematol., 85, 718-722.

Bélair, J. and Mackey, M. (1987). A model for the regulation of mammalian platelet. Ann. N. Y. Acad. Sci., 504

Bélair, J., Mackey, M. and Mahaffy, J. (1995). Age-structured and two-delay models for erythropoiesis. Math. Biosci., 128, $317-346$.

Bernard, J. and Caen, J. (1962). Purpura thrombopénique et megacaryocy-topénie cycliques mensuels. Nouv. Rev. franc. Hémat., 2, 378-386.

Beutler, E., Lichtman, M. A., Coller, B. S. and Kipps, T. J. (1995). Williams Hematology., McGraw-Hill, New York.

Borge, O., Ramsfjell, V., Cui, L. and Jacobsen, S. (1997). Ability of early acting cytokines to directly promote survival and suppress apoptosis of human primitive CD34+CD38-bone 
marrow cells with multilineage potential at the single cell level: Key role of thrombopoietin. Blood, 90, 2282.

Borge, O., Ramsfjell, V., Veiby, O., Murphy, M., Lok, S, and Jacobsen, S. (1996). Thrombopoietin, but not erythropoietin promotes vjability and inhibits apoptosis of multipotent murine hematopoietic progenitor cells in vitro. Blood, $\mathbf{8 8}, 2859-2870$.

Branehog, I., Kutti, J., Ridell, B., Swolin, B. and Weinfeld, A. (1975). The relation of thrombokinetics to bone marrow megakaryocytes in idiopathic thrombocytopenic purpura (ITP). Blood, 45, 552-562.

Brey, O., Garner, E. P. R. and Wells, D. (1969). Cyclic thrombocytopenia associated with multiple antibodies. Brit. Med. J. 3, 397-398.

Broudy, V. and Kaushansky, K. (1995). Thrombopoietin, the cMpi ligand, is a major regulator of platelet production. Journal of Leukocyte Biology, 57, 719-725.

Bussel, J., Fitzgerald-Pedersen, J. and Feldman, C. (1990). Alternation of two duses of intravenous gamma globulin in the maintenance treatment of patients with immune thrombocytopenic purpura: More is not always better. American Journal of Hematology, 33, 184-188.

Caen, J., Meshaka, G., Larrieu, M. J. and Bernard, J. (1964). Les purpuras thrombopéniques intermittents idiopathiques. Sem. Hôp. Paris, 40, 276-282.

Chintagumpala, M., Hurwitz, R,, Moake, J., Mahoney, D. and Steuber, C. (1992). Chroric relapsing thrombotic thrombocytopenic purpura in infants with large von Willebrand factor multimers during remission. I. Pediatr.

Cohen, T. and Cooney, D. P. (1974). Cyclical thrombocytopenia: Case report and review of literature. Scand. J. Haemat. 16. $133-138$

Dan, K., Inokuchi, K., An, E. and Nomura, T. (1991). Cell mediated cyclic thrombocytopenia treated with azathioprine. Brit. J. Haematol. 77, 365-379.

Demmer, T. (1920). Morbus maculosus werthofii in regeimassigen vierwochentlichen schüben bei einem 60 jahrigen mann nebst untersuchungen über die blutplattchen. Folia Haemat., 26, 74-86.

Eaton, D. and de Sauvage, F. (1997). Thrombopoietin: The primary regulator of megakaryocytopoiesis and thrombopoiesis Exper, Hematol., 25, 1-7.

Eller, J., Györi, I., Zollei, J. and Krizsa, F. (1987). Modelling thrombopoiesis regulation I: Model description and simulation results. Comput. Math. Applic., 14, 841-848.

Ellis, M., Avraham, H. and Groopman, J. (1995). The regulation of megakaryocytopoiesis. Blood Reviews, 9, 1-6.

Engstrom, K., Lundquist, A. and Soderstrom, N. (1966). Periodic thrombocytopenia or tidal platelet dysgenesis in a man. Scand. J. Haemat., 3, 290-292.

Fortin, P. and Mackey, M. (1999). Periodic chronic myelogenous leukemia: Spectral analysis of blood cell counts and etjological implications. Brit. J. Haematol., (in press).

Glass, L. and Mackey, M. (1988). From Clocks to Chaos: The Rhythms of Life. Princeton University Press, Princeton, N.J.

Goldschmidt, B. and Fono, R. (1972). Cyclic fluctuations in platelet count, megakaryocyte maturation and thrombopoietin activity in cyanotic congenital heart disease. Acta. Paediat. Scand, 61, 310-314.

Gray, W. and Kirk, J. (1971). Analysis by analogue and digital computers of the bone marrow stem cell and platelet control mechanisms. In Proc. Conf. Computers for Analysis and Control in Medical and biological Research, UK. IEE.. pages $120-124$.

Györi, I. and Eller, J. (1987). Modelling thrombopoiesis regulation II: Mathematical investigation of the model. Comput. Math. Applic., 14, 849-859.
Haurie, C., Dale, D. C. and Mackey, M. (1999a). Occurrence of periodic oscillations in the differential blood counts of congenital, idiopathic and cyclical neutropenic patients before and during treatment with G-CSF. Exper. Hematol, 27, 401-409. Haurie, C. and Mackey, M. (1999). Modeling complex neutrophil dynamics in the grey collie. J. theor. Biol. (submitted).

Haurie, C., Mackey, M. C. and Dale, D. C. (1998). Cyclical neutropenia and other periodic bematological diseases: A review of mechanisms and mathematical models. Blood, 92, $2629-2640$.

Haurie, C., Person, R., Dale, D. C. and Mackey, M. (1999b). Haematopoietic dynamics in grey collies. Exper. Hematol, (in press).

Hearn, T., Haurie, C. and Mackey, M. (1998). Cyclical neutropenia and the peripheral control of white blood cell production. J. theor. Biol, 192, 167-181.

Helleberg, C., Taaning, E. and Hansen, P. (1995). Cyclical thrombocytopenia successfully treated with low dose hormonal contraception. American Journal of Hematology, 48, 62-63.

Hoffman, R. (1989). Regulation of megakaryocytopoiesis. Blood, 74, $1196-1212$

Hoffman, R., Bridell, R., van Besien, K., Srour, E., Guscar, T., Hudson, N. and Ganser, A. (1989). Acquired cyclic amegakaryocytic thrombocytopenia associated with an immunoglobulin blocking the action of granulocytemacrophage colonystimulating factor. New England Journal of Medicine, 321. $97-102$.

Kaushansky, K. (1995). Thrombopoietin: The primary regulator of platelet production. Blood, 86, 419-431.

Kaushansky, K., Broudy, V., Lin, N., Jorgensen, M., McCarty, J., Fox, N., Zucker-Franklin, D. and Lofton-Day, C. (1995). Thrombopoietin, the Mpl ligand, is essential for full megakaryocyte development. Proc. Natl. Acad. Sci. U.S.A., 92 , $3234-3238$.

Kimura, F., Nakamura, Y., Sato, K., Wakimoto, N., Kato, T., Tahara, T., Yamada, M., Nagata, N. and Motoyoshi, K. (1996). Cyclic change of cytokines in a patient with cyclic thrombocytopenia. British Joumal of Haematology, 94 $171-174$

Kirk, J., Orr, J. S, and Hop, C. S. (1968). A mathematical analysis of red blood cell and bone marrow stem cell control mechanism. British Journal of Hoematology, 15, 35-46.

Kosugi, S., Tomiyama, Y., Shiraga, M., Kashiwagi, H., Nakao, H., Kanayama, Y., Kurata, Y. and Matsuzawa, Y. (1994). Cyclic thrombocytopenia associated with IgM and anti-GPIIbIIIa autoantibodies. British Journal of Haematology, 88, 809-815.

Kuter, D. (1996). The physiology of platelet production. Stem Cells, 14, 88-101.

Kuter, D., Hunt, S. and Zucker-Franklin, D. (1997). Thrombopoiesis and Thrombopoietins., Humana Press.

Kuter, D. and Rosenberg, R. (1995). The reciprocal relationship of thrombopoietin (c-Mpl ligand) to changes in the platelet mass during busulfan induced thrombocytopenia in the rabbit. Blood, 85, 2720-2730.

Layton, J., Hockman, H., Sheridan, W. and Morstyn, G. (1989). Evidence for a novel in vivo control mechanism of granulopoiesis: Mature cell-related control of a regulatory growth factor. Blood, 74, 1303-1307.

Lewis, M. L. (1974). Cyclic thrombocytopenia: A thrombopoietin deficiency. J. Clin. Path, 27, 242-246.

Mackey, M. C. (1978). A unified hypothesis for the origin of aplastic anemia and periodic haematopoiesis. Blood, $\mathbf{5 1}$, 941-956.

Mackey, M. C. (1979a). Dynamic haematological disorders of stem cell origin. In Vassileva-Popova, J. G. and Jensen, E. V.. 
editors, Biophysical and Biochemical Information Transfer in Recognition, Plenum Publishing Corp., New York, pages 373-409.

Mackey, M. C. (1979b). Periodic auto-immune hemolytic anemia: An induced dynamical disease. Butl. Math. Biol., 41, 829-834.

Mackey, M. C. (1996). Mathematical models of hematopoietic cell replication and control. In Othmer, H., Adler, F., Lewis, M. and Dallon, J,, editors, The Art of Mathematical Modeling: Case Studies in Ecology, Physiology and Biofuids. Prentice Hall, New York, pages 149-178.

Mahaffy, J. M., Bélair, J. and Mackey, M. (1998). Hematopoietic model with moving boundary condition and state dependent delay. J. theor. Biol., 190, 135-146.

Menitove, J., Pereira, J., Hoffman, R., Anderson, T., Fried, W. and Aster, R. (1989). Cyclic thrombocytopenia of apparent autoimmune etiology. Blood, 73, 1561-1569.

Morley, A. (1969). A platelet cycle in normal individuals. Aust. Ann. Med., 18, 127-129.

Ort, J. S., Kirk, J., Gray, K. and Anderson, J. (1968). A study of the interdependence of red cell and bone marrow stem cell populations. British Journal of Haematology, 15, 23-24.

Papayannopoulou, T. (1996). Biologic effects of thrombopoietin, the $\mathrm{Mpl}$ ligand, and its therapeutic potential. Cancer Chemother. Pharmacol, 38, S69-S73.

Press, W., Teukolsky, S., Vetterling, W. and Flannery, B. (1992). Numerical recipes in C, 2 nd edition., Cambridge University.

Ratajczak, M., Ratajczak, I., Marlicz, W., Pletcher, C., Machalinski, B., Moore, J., Hung, H. and Gewirtz, A. (1997). Recombinant human thrombopoietin (TPO) stimulates erythropoiesis by inhibiting erythroid progenitor cell apoptosis. British Journal of Haematology, 98, 8-17.

Ritchie, A., Gotoh, A., Gaddy, J., Braun, S. and Broxmeyer, H. (1997). Thrombopoietin upregulates the promoter conformation of $p 53$ in a proliferation-independent manner coincident with a decreased expression of bax: potential mechanisms for survival enhancing effects. Blood, 90, 4394-4402.

Ritchie, A., Vadhan-Raj, S, and Broxmeyer, H. (1996). Thrombopoietin suppresses apoptosis and behaves as a survival factor for the human growth factor-dependent cell line, M07e. Stem Cells, 14, 330-336.

Rocha, R., Horstman, L., Ahn, Y., Mylvaganam, R. and Harrington, W. (1991). Danazol therapy for cyclic thrombocytopenia. American Journal of Hematology, 36, 140-143.

Scargle, J. D. (1982). Studies in astronomical time series analysis. II. statistical aspects of spectral analysis of unevenly spaced data. The Astrophysical Journal, 263, 835-853.

Sitnicka, E., Lin, N., Priestley, G., Fox, N., Broudy, V., Wolf, N. and Kaushansky, K. (1996). The effect of thrombopoietin on the proliferation and differentiation of murine hematopoietic stem cells. Blood, 87, 4998-5005.

Skoog, W. A., Lawrence, J. S. and Adams, W. S. (1957). A metabolic study of a patient with idiopathic cyclical thrombocytopenic purpura. Blood, 12, 844-856.

Snedecor, G. and Cochran, W. (1980). Statistical Methods, 7th edition., Iowa State University Press.

Solar, G., Kerr, W., Zeigler, F., Hess, D., Donahue, C., de Sauvage, F. and Eaton, D. (1998). Role of c-Mpl in early hematopoiesis. Blood, 92, 4-10.

Tanimukai, S., Kimura, T., Sakabe, H., Ohmizono, Y., Kato, T. Miyazaki, H., Yamagishi, H. and Sonoda, Y. (1997). Recombinant human c-Mpl ligand (thrombopoietin) not only acts on megakaryocyte progenitors, but also on erythroid and multipotential progenitors in vitro. Exper. Hematol., 25, 1025-1033.

Tefferi, A., Solberg, L., Petitt, R. and Willis, L. (1989). Adult onset cyclic bicytopenia: A case report and review of treatment of cyclic hematopoiesis. Am. J. Hematol, 30, 181-185.

Tomer, A., Schreiber, A., McMillan, R., Cines, D., Burstein, S. Thiessen, A. and Harker, L. (1989). Menstrual cyclic thrombocytopenia. British Journal of Haematology, 71, 519-524.

von Schulthess, G. and Gessner, U. (1986). Oscillating platelet counts in healthy individuals: Experimental investigation and quantitative evaluation of thrombocytopoietic feedback control. Scand. J. Haematol., 36, 473-479.

Wasastjerna, C. (1967). Cyclic thrombocytopenia of acute type. Scand. J. Haemat., 4, 380-384.

Wichmann, H., Gerhardts, M., Spechtmeyer, H. and Gross, R. (1979). A mathematical model of thrombopoiesis in the rat. Cell Tissue Kinet, 12, 551-567.

Wilkinson, T. and Firkin, B. (1966). Idiopathic cyclical acute thrombocytopenic purpura. Med. J. Aust., 1, 217-219.

Yanabu, M., Nomura, S., Fukuroi, T., Kawakatsu, T., Kido, H., Yamaguchi, K., Suzuki, M., Kokawa, T. and Yasunaga, K (1993). Periodic production of antiplatelet autoantibody directed against GP IIIa in cyclic thrombocytopenia. Acta Haematol., 89, 155-159.

Zauli, G., Vitale, M. Falcieri, E., Gibellini, D., Bassini, A., Celeghini, C.. Columbaro, M. and Capitani, S. (1997). In vitro senescence and apoptotic cell death of human megakaryocytes. Blood, 90, 2234-2243.

Zeigler, F., de Sauvage, F., Widmer, H., Keller, G., Donahue, C., Schreiber, R., Malloy, B., Hass, P., Eaton, D. and Matthews, S. (1994). In vitro megakaryocytopoietic and thrombopoietic activity of c-Mpl ligand (TPO) on purified murine hematopoietic stem cells. Blood, 84, 4045-4052. 


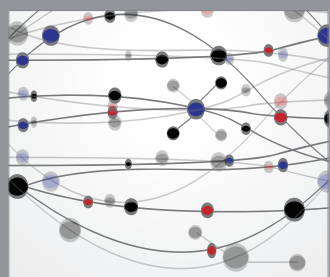

The Scientific World Journal
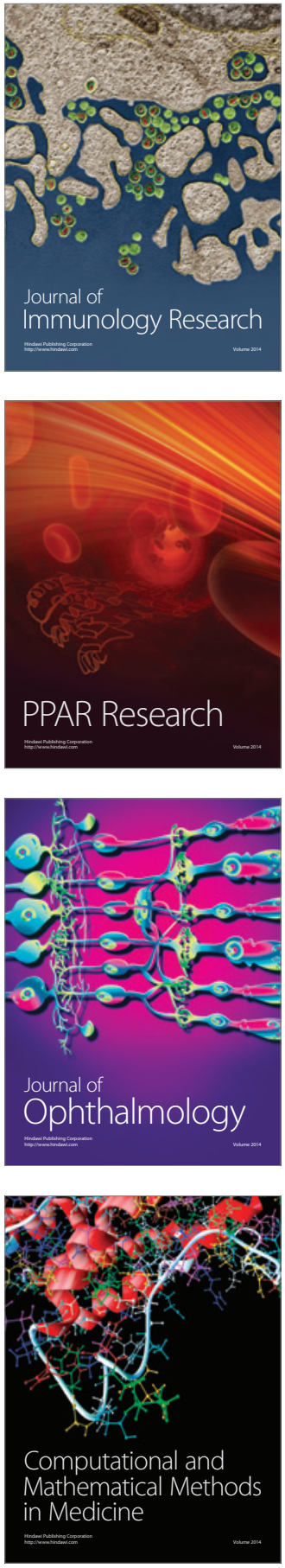

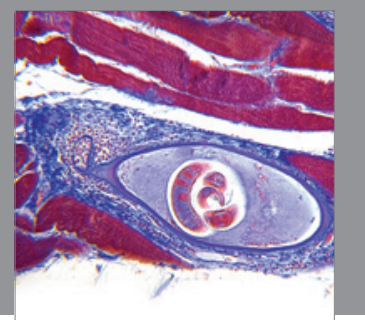

Gastroenterology

Research and Practice
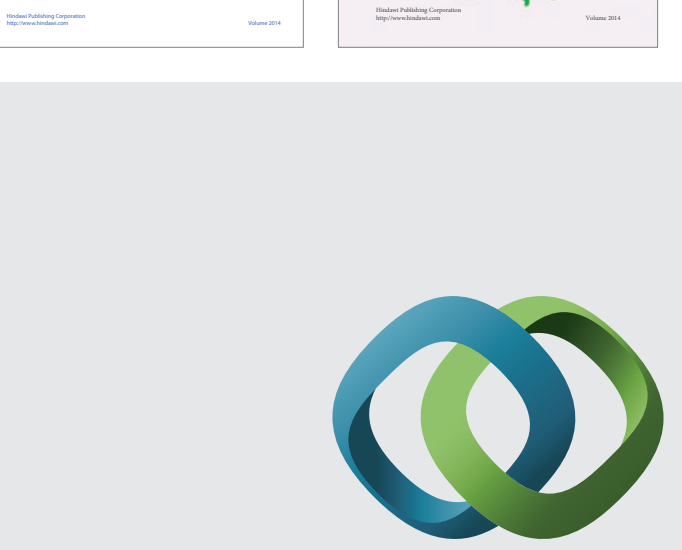

\section{Hindawi}

Submit your manuscripts at

http://www.hindawi.com
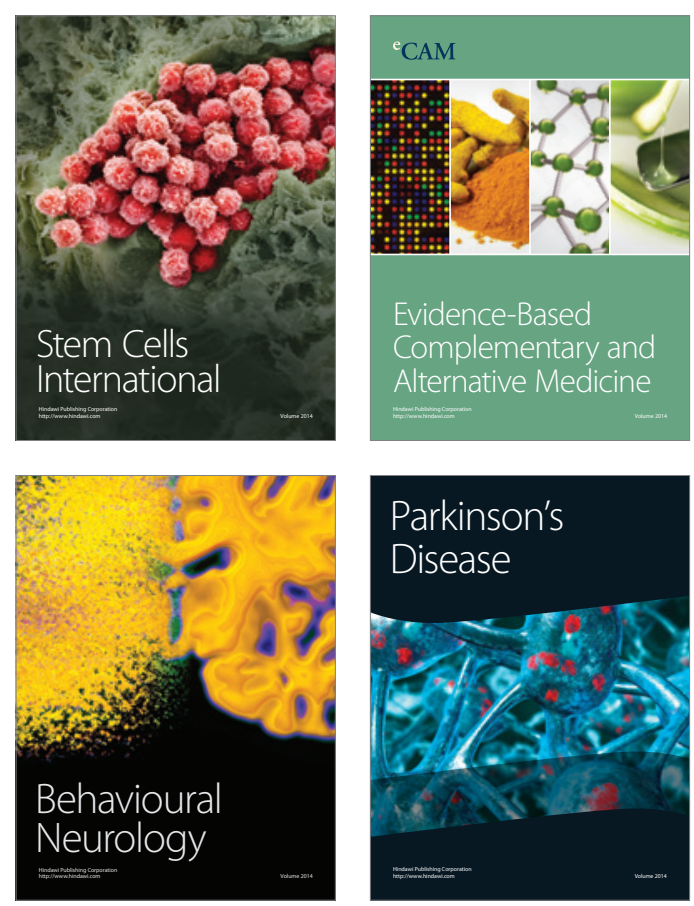

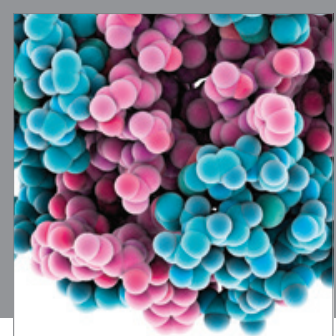

Journal of
Diabetes Research

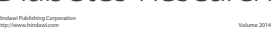

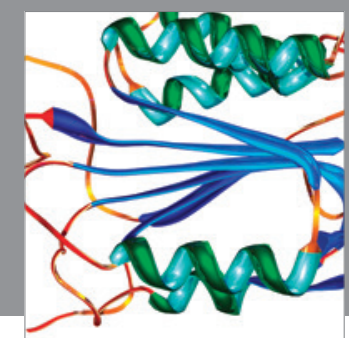

Disease Markers
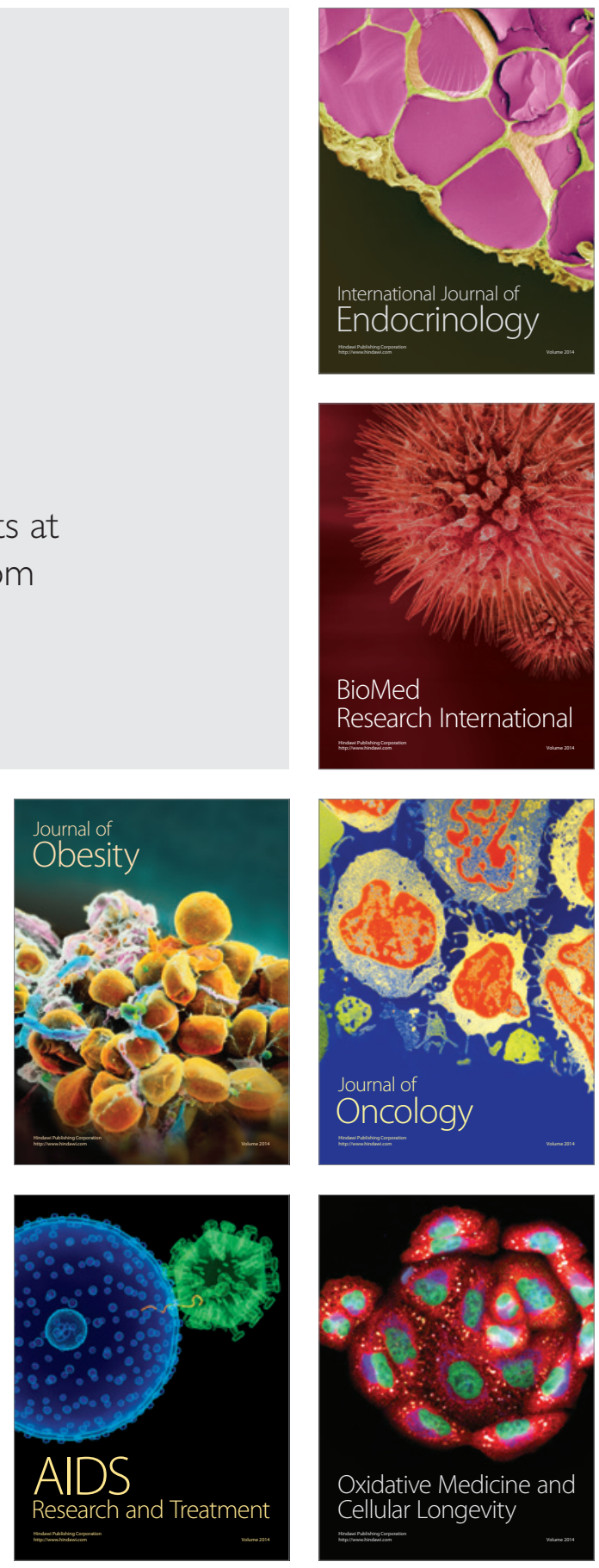